03,08

\title{
Взаимодействие атомов сурьмы с микропорами в кремнии
}

\author{
(C) В.Б. Оджаев ${ }^{1}$, А.Н. Петлицкий ${ }^{2}$, В.И. Плебанович ${ }^{3}$, П.К. Садовский ${ }^{1}$, \\ М.И. Тарасик ${ }^{1}$, А.P. Челядинский ${ }^{1, ף}$ \\ ${ }^{1}$ Белорусский государственный университет, \\ Минск, Беларусь \\ ${ }^{2}$ ОАО „Интеграл“, \\ Минск, Беларусь \\ ${ }^{3}$ ОАО „ПЛАНАР“, \\ Минск, Беларусь \\ `E-mail: chelyadinski@bsu.by \\ (Поступила в Редакцию 11 апреля 2017 г.)
}

Исследовано взаимодействие атомов $\mathrm{Sb}$ с микропорами геттерного слоя в кремнии. Геттерный слой создавался путем имплантации в кремний ионов $\mathrm{Sb}^{+}$и последующих термообработок. Обнаружено, что атомы сурьмы, расположенные в окрестности микропор, захватываются на микропоры в процессе геттерирующего отжига и теряют электрическую активность. Энергия активации процесса захвата сурьмы на поры ниже энергии активации диффузии сурьмы в кремнии. Это объясняется влиянием на процесс диффузии полей упругих деформаций вокруг микропустот.

DOI: 10.21883 /FTT.2018.01.45283.123

\section{1. Введение}

Обладая глубокими энергетическими уровнями в запрещенной зоне кремния, примеси переходных металлов $(\mathrm{Cu}, \mathrm{Fe}, \mathrm{Ni}$ и др.) влияют на генерационно-рекомбинационные процессы и тем самым ухудшают электрофизические параметры приборов, снижают показатели выхода годных изделий микро- и оптоэлектроники $[1,2]$. Эффективными геттерами неконтролируемых примесей в кремнии являются его пористые слои. Эти слои создаются преимущественно на нерабочей стороне пластины путем имплантации ионов $\mathrm{H}^{+}$либо $\mathrm{He}^{+}$и последующих термообработок, обеспечивающих создание микрополостей [3]. Для создания слоя пористого кремния может использоваться также имплантация стандартной для микроэлектронного производства примеси ионов $\mathrm{Sb}^{+} \mathrm{c}$ последующими термообработками [4].

В отличие от имплантированных примесей $\mathrm{He}^{+}$и $\mathrm{H}^{+}$, которые при отжиге уходят из слоя на поверхность, примесь сурьмы после термообработок остается в слое кремния с геттером. Поэтому представляется целесообразным изучить возможное взаимодействие примеси сурьмы с микропорами геттерного слоя во время термообработок при различных температурах.

\section{2. Методика эксперимента}

Ионно-легированные слои создавались в монокристаллических пластинах кремния $p$-типа проводимости с удельным сопротивлением $\rho_{0}=10 \Omega \cdot \mathrm{cm}$ путем имплантации ионов сурьмы с энергией $60 \mathrm{keV}$, доза ионов $2.4 \cdot 10^{15} \mathrm{~cm}^{-2}$. Термообработка проводилась в атмосфере смеси азота с кислородом. Предварительно для создания защитного слоя $\mathrm{SiO}_{2}$ пластины отжигались при температуре $850^{\circ} \mathrm{C}$ в атмосфере кислорода в течение $15 \mathrm{~min}$.

Имплантированные сурьмой слои отжигались при температуре $1000^{\circ} \mathrm{C}$. Вследствие значительного превышения концентрации сурьмы предела растворимости возникали области скоплений второй фазы металлической сурьмы. Электрическая активация сурьмы в силу этого составляла 21\%. Затем проводилась термообработка при $1220^{\circ} \mathrm{C}$. Вследствие диффузии сурьмы атомы примеси покидали области скоплений, оставляя микропоры. Электрическая активация примеси в пластинах, отожженных при $1220^{\circ} \mathrm{C}$ составляла практически $100 \%$.

Электрическая активация внедренных примесей исследовалась путем измерения эффекта Холла и проводимости по методике Ван-дер-Пау [5]. Время жизни неравновесных носителей заряда измерялось фазовым СВЧ-методом [6] с объемным возбуждением носителей заряда. Источником возбуждения служил светодиод с длиной волны излучения $0.9 \mu \mathrm{m}$. Измерения проводили при низком уровне возбуждения. Для уменьшения влияния поверхности на рекомбинацию носителей заряда пластины кремния выдерживались в 2\% растворе $\mathrm{KMnO}_{4}$ в ацетоне.

\section{3. Результаты экспериментов и их обсуждение}

Для изучения взаимодействия атомов сурьмы с микропорами пластины кремния со сформированным геттерным слоем подвергались отжигу в течение $30 \mathrm{~min}$ в атмосфере азота с кислородом при температурах $700^{\circ} \mathrm{C}$, $800^{\circ} \mathrm{C}, 900^{\circ} \mathrm{C}$ и $1000^{\circ} \mathrm{C}$.

На рис. 1 показан профиль распределения сурьмы в слое кремния, отожженном при температуре $1220^{\circ} \mathrm{C}$. 


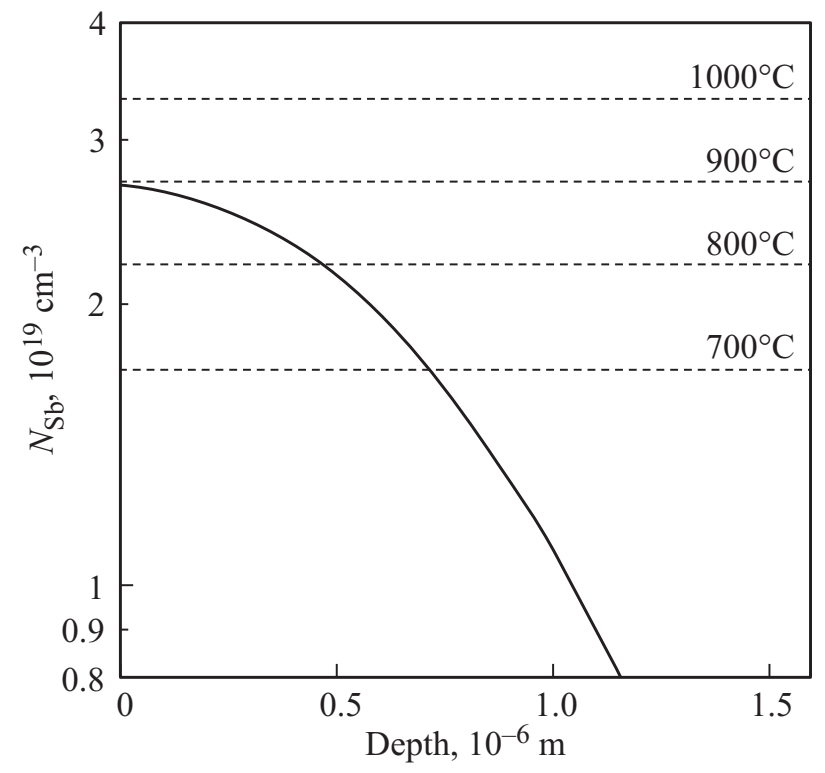

Рис. 1. Профиль распределения примеси $\mathrm{Sb}$, в кремнии (сплошная линия), пунктирные линии - предел растворимости $\mathrm{Sb}$ в $\mathrm{Si}$ при различных температурах.

Здесь же показаны пределы растворимости сурьмы в кремнии при температурах $700^{\circ} \mathrm{C}, 800^{\circ} \mathrm{C}, 900^{\circ} \mathrm{C}$ и $1000^{\circ} \mathrm{C}$ [7]. Результаты измерений электрической активации сурьмы после термообработок представлены в таблице.

При повышении температуры отжига возрастает доля электрически неактивной примеси сурьмы. При этом объемная концентрация сурьмы до проведения отжигов $\left(700-900^{\circ} \mathrm{C}\right)$ находилась ниже предела растворимости при температурах 900 и $1000^{\circ} \mathrm{C}$. С другой стороны при температуре отжига $700^{\circ} \mathrm{C}$ наблюдается почти полная электрическая активация сурьмы (99\%), несмотря на то, что исходная концентрация примеси в слое превышала предел растворимости. Практически полное отсутствие деактивации сурьмы при отжиге $700^{\circ} \mathrm{C}$ связывается с низким коэффициентом диффузии при этой температуре. Оценки показали, что среднее расстояние между атомами сурьмы в кремнии при дозе имплантации $2.4 \cdot 10^{15} \mathrm{~cm}^{-2}$ и отжиге при $1220^{\circ} \mathrm{C}(14 \AA)$ превышает расстояние диффузионного пробега атома $\mathrm{Sb}$ при темпе-

Слоевая концентрация $N_{S}$ носителей заряда в кремнии, имплантированном ионами $\mathrm{Sb}^{+}$после термообработок

\begin{tabular}{c|c|c}
\hline $\begin{array}{c}\text { Температура } \\
\text { отжига, }{ }^{\circ} \mathrm{C}\end{array}$ & $\begin{array}{c}N_{S} \text { электрически } \\
\text { активной } \mathrm{Sb}, \\
10^{15} \mathrm{~cm}^{-2}\end{array}$ & $\begin{array}{c}\text { Электрическая } \\
\text { активация } \\
\text { примеси } \mathrm{Sb}, \%\end{array}$ \\
\hline Не проводился & 2.40 & 100 \\
700 & 2.35 & 99 \\
800 & 2.30 & 97 \\
900 & 2.23 & 94 \\
1000 & 2.09 & 88
\end{tabular}

ратуре $700^{\circ} \mathrm{C}$ в течение $30 \min (2 \AA)$. Коэффициент диффузии сурьмы при $700^{\circ} \mathrm{C}$ оценивался из экстраполяции его температурной зависимости [8].

На рис. 2 представлена зависимость в логарифмическом масштабе слоевой концентрации электрически неактивной примеси $\mathrm{Sb}$ от $1 / k T$, линейный вид которой позволяет определить энергию активации данного процесса. Деактивация примеси сурьмы при отжиге, когда ее концентрация ниже предела растворимости, объясняется миграцией и захватом атомов $\mathrm{Sb}$ на оборванные связи микропустот. Значение энергии активации процесса захвата примеси сурьмы во время отжига, определенное из зависимости, представленной на рис. 2 , составило $0.9 \mathrm{eV}$. Полученное значение меньше энергии активации диффузии сурьмы в кремнии $E_{\text {dif }}=3.65 \mathrm{eV}[9]$.

Необходимо отметить, что не только атомы сурьмы захватываются на микропоры в кремнии. В работе [10] наблюдался захват примеси бора на поры, созданные имплантацией ионов $\mathrm{He}^{+}$. Параллельные исследования методом SIMS и методом электрических измерений позволили заключить, что захваченные на микропоры атомы бора не являются электрически активными. В работе [10] отмечается достаточно большое количество атомов бора, захваченных на микропоры даже при небольших длительностях (10s) быстрого термического отжига. Авторы $[10,11]$ отмечали, что захват бора на микропоры протекает при ускоренной диффузии бора. Именно в силу этого в захвате на микропоры могут участвовать все атомы бора в имплантированном слое. Ускоренная диффузия связывается с точечными дефектами междоузельного типа, образующимися при распаде остаточных протяженных нарушений (дефекты упаковки

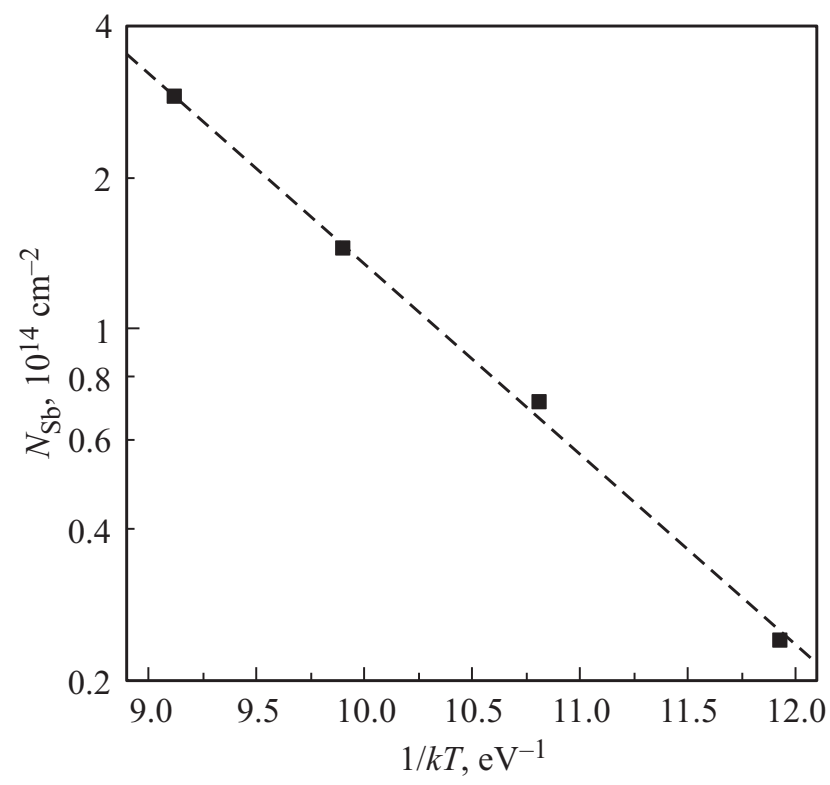

Рис. 2. Зависимость слоевой концентрации электрически неактивной примеси $\mathrm{Sb}$ от $1 / k T$. 


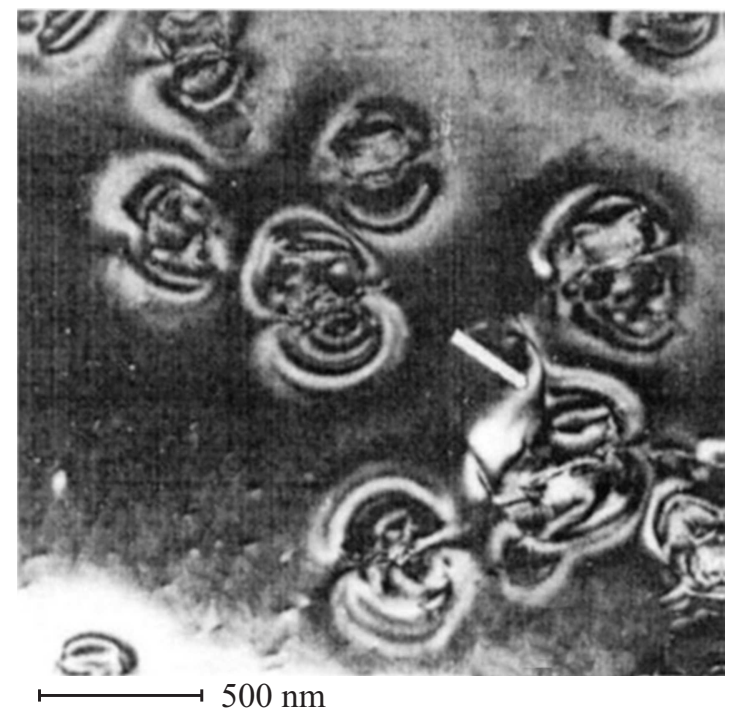

Рис. 3. ПЭМ-изображение полей упругих деформаций решетки кремния, возникающих вокруг микропор в кремнии [13].

внедренного типа, дислокационные петли). Действительно, в кремнии, имплантированном ионами $\mathrm{He}^{+}$большими дозами, при последующей термообработке из точечных дефектов образуются остаточные нарушения. Образующиеся поры несколько снижают ускоренную диффузию за счет захвата междоузельных атомов $\mathrm{Si}$. В случае же имплантации тяжелых ионов $\mathrm{Sb}^{+}$происходит аморфизация слоя внедрения. При последующей термообработке и рекристаллизации аморфного слоя образования точечных дефектов в заметных концентрациях не происходит. Более того, из исследований, выполненных в работе [12], следует, что введение точечных дефектов (облучение ионами $\mathrm{Si}^{+}$) в слои кремния, легированные сурьмой, не приводит к значительному увеличению ее коэффициента диффузии.

Тем не менее, наблюдается существенное снижение энергии активации миграции атомов сурьмы. Этот эффект может быть связан с воздействием на атомы примеси полей упругих деформаций решетки кремния [13], возникающих вокруг микропор (рис. 3). Поля упругих деформаций зарегистрированы с помощью электронной микроскопии высокого разрешения [13]. Как видно из таблицы, даже при отжиге в течение $30 \mathrm{~min}$ при $1000^{\circ} \mathrm{C}$ на поры захватывается всего $12 \%$ атомов сурьмы, тогда как из пор во время их формирования уходит 79\% примеси.

Трудно оценить, как воздействуют атомы сурьмы, захваченные на оболочку микропоры, на сечение захвата атомов неконтролируемых примесей. Однако измеренное время жизни неравновесных носителей заряда в пластинах с геттерным слоем $(12-15 \mu \mathrm{s})$ значительно превышает время жизни в исходных пластинах $(3.4-3.5 \mu \mathrm{s})$. Эти значения являются усредненными по всей пластине. Время геттерирования составляло $5 \mathrm{~h}$ при температуре $1000^{\circ} \mathrm{C}$. Значительное увеличение времени жизни неравновесных носителей заряда говорит о высокой эффективности геттерирования. Как влияет захват на микропоры атомов бора на эффективность геттерирования в работе [10] не сообщается.

\section{4. Заключение}

Таким образом, установлено, что атомы сурьмы при термообработках при $700-1000^{\circ} \mathrm{C}$ взаимодействуют с микропустотами пористого кремния, созданного путем имплантации ионов сурьмы и последующих термообработок. Энергия активации процесса захвата сурьмы на поры оказалась ниже энергии активации диффузии сурьмы в кремнии, что связывается с влиянием на процесс диффузии полей упругих деформаций вокруг микропустот.

\section{Список литературы}

[1] D. Macdonald, A.Y. Linand, S.P. Phang. Mater. In: Int. Conf. Gettering and Defect Engineering in Semiconductor Technology XV. Oxford, UK. (2013). P. 26.

[2] A. Kinomura, R. Suzuki, T. Ohdaira, M. Muramatsu, C. He, N. Oshima, T. Matsumoto, H. Tanoue, Y. Horino. J. Appl. Phys. 104, 034301 (2008).

[3] S.E. Donnelly, V.M. Vishnyakov, G. Carter, J. Terry, L.I. Haworth, P. Sermannic, R.C. Birtcher. Mater. Sci. Eng. B 206, 422 (2003).

[4] П.К. Садовский, А.Р. Челядинский, В.Б. Оджаев, М.И. Тарасик, А.С. Турцевич, Ю.Б. Васильев. ФТТ 55, 1071 (2013).

[5] L.J. Van der Pauw. Philips Res. Rep. 13, 1 (1958).

[6] А.В. Бураков, С.Н. Якубеня, А.М. Янченко. ПТЭ 4, 226 (1986).

[7] F.A. Trumbore. Bell. Syst. Tech. J. 39, 205 (1960).

[8] Atomic diffusion in Semiconductors / Ed. D. Shaw. Plenum Press, London-N. Y. (1973).

[9] К. Пирс, А. Адамс, Л. Кац, Дж. Цай, Т. Сейдел, Д. Макгиллис. Технология СБИС. Т. 1. Мир, М. (1986). С. 40.

[10] F. Roqueta, D. Alquier, L. Ventura, Ch. Dubois, R. Jerisian. Nucl. Instr. Meth. Phys. Res. B 183, 318 (2001).

[11] J. Wong-Leung, J.S. Williams, M. Petravic. Appl. Phys. Lett. 72, 2418 (1998).

[12] М. Джадан, А.Р. Челядинский, В.Ю. Явид. Микроэлектроника 41, 2, 98 (2012).

[13] T. Akiyama, Y. Okamoto, M. Saito, A. Oshiyama. Jpn. J. Appl. Phys. 38, 1363 (1999). 